\title{
PERANCANGAN MESIN PEMILAH SAMPAH KAPASITAS 50 KG/JAM
}

\section{Tri Noviyanto, Eka Maulana, Eddy Djadmiko}

Universitas Pancasila, Jakarta, Indonesia

Email: trinoviyan0511@gmail.com, ekamaulana@gmail.com, eddydjatmiko@gmail.com

\begin{abstract}
Abstrak
Dalam pengolahan sampah baik sampah organik maupun sampah non organik yang biasanya didapatkan masih dalam kondisi tercampur sehingga dapat disortir terlebih dahulu untuk proses pengolahan lebih lanjut. Penyortiran sampah dapat dilakukan dengan cara yang sederhana, baik manual atau menggunakan alat secara otomatis. Tujuan penelitian ini adalah menghasilkan rancangan mesin pemilah sampah dengan kapasitas $50 \mathrm{~kg} / \mathrm{jam}$ fungsi dari alat yaitu sebagai pemilah sampah dengan cara pengayakan (screen) proses sortasi berdasarkan ukuran serta bentuk alat ini merupakan ayakan dinamis dengan posisi miring, berotasi dengan kecepatan rendah alat pemilah ini biasanya dipergunakan untuk memilah berbagai jenis material dikarnakan terdapat dua atau lebih aliran dengan berbagai jenis. Untuk menghasilkan rancangan tersebut dengan menggunakan metode perancangan French, dari perancangan konsep mesin pemilah sampah kapasitas $50 \mathrm{~kg} / \mathrm{jam}$, pada perancangan konsep ini bertujuan untuk menghasilkan pilihan-pilhan alternatif dari konsep yang dibuat didapat perhitungan varian yaitu perhitungan perancangan nilai varian pada varian 1 adalah 3,90 dan varian 2 adalah 4,08. Maka perancangan mendapatkan nilai terpilih pada varian 2 dengan bobot penilaian 4,08. Data hasil perhitungan motor listrik untuk memutar rangka ayakan dan mash sebesar $2 \mathrm{~kg}$ sekitar 0,5 HP.
\end{abstract}

Kata Kunci: sampah; metode french; mesin pemilah

\section{Abstract}

In waste processing, both organic and non-organic waste are usually obtained in mixed conditions so that they can be sorted first for further processing. Sorting waste can be done in a simple way, either manually or using an automatic tool. The purpose of this research is to produce a waste sorting machine design with a capacity of $50 \mathrm{~kg} / \mathrm{hour}$. The function of the tool is to sort waste by means of screen sorting. The sorting process based on the size and shape of this tool is a dynamic sieve with a tilted position, rotating at a low speed. usually used to sort various types of material because there are two or more streams of various types. To produce this design using the French design method, from the design of the concept of sorting the waste capacity of $50 \mathrm{~kg} / \mathrm{hour}$, the design of this concept aims to produce alternative choices from the concept made obtained by calculating the calculation of the calculation of variance in the design of variant 1 is 3,90 and variant 2 is 4,08. Then the design gets the selected assessment at the 4,08 weight

$\begin{array}{ll}\text { How to cite: } & \text { Noviyanto. T., Maulana, E., \& Djatmiko, E. (2021) Perancangan Mesin Pemilah Sampah Kapasitas 50 } \\ & \text { Kg/Jam. Syntax Literate: Jurnal Ilmiah Indonesia, 6(10). http://dx.doi.org/10.36418/ Syntax- } \\ & \text { Literate.v6i10.4313 } \\ \text { E-ISSN: } & \text { 2548-1398 } \\ \text { Published by: } & \text { Ridwan Institute }\end{array}$


assessment. The data from the calculation of the electric motor to rotate the sieve frame and mash of $2 \mathrm{~kg}$ is about $0.5 \mathrm{HP}$.

Keywords: garbage; french method; sorting machine

Received: 2021-09-20; Accepted: 2021-10-05; Published: 2021-10-20

\section{Pendahuluan}

Sampah adalah suatu permasalahan yang nyata pada zaman ini seiring bertumbuhnya populasi manusia yang terus bertambah, pertumbuhan sampah yang setiap hari semakin meningkat ini akan mengakibatkan danpak buruk bagi lingkungan jika tidak diolah dengan baik. Sampah berasal dari berbagai sumber seperti sampah rumah tangga dari sumber perumahan, komersial, dan juga industri (Sampah Perkotaan, 2016). Sampah industri disebut sebagai limbah kota dan sering dianggap sebagai bahan yang dihasilkan didaerah perkotaan yang tidak cocok untuk penggunaan bermanfaat lebih lanjut, dan dimaksudkan untuk dibuang, dibakar, didaur ulang dengan cara tertentu atau dianggap menyatu seperti limbah (Purwaningrum, 2016).

Komposisi sampah yang dihasilkan dari aktivitas manusia adalah sampah organik sebanyak 60-70\% dan sisanya adalah sampah non organik 30-40\%, sementara itu dari sampah non organik tersebut komposisi sampah terbanyak kedua yaitu sebesar $14 \%$ adalah sampah plastic (Purwaningrum, 2016). Sampah non organik seperti kertas, karton, benang, kain, kayu, logam, kaca plastik, karet dan sebagainya serta sampah organik seperti sisa-sisa makanan dan sisa masakan, jika bisa ditangani dengan baik atau di olah dengan baik serta efisien bukan hanya dapat mengatasi masalah-masalah yang ditimbulkan olah sampah namun dapat menggembangkan potensi ekonomi dari sampah (Mulyadin, Iqbal, \& Ariawan, 2018).

Dalam pengolahan sampah baik sampah organik maupun sampah non organik yang biasanya didapatkan masih dalam kondisi tercampur sehingga dapat disortir terlebih dahulu untuk proses pengolahan lebih lanjut. Penyortiran sampah dapat dilakukan dengan cara yang sederhana baik manual atau menggunakan alat secara otomatis (Putu Agus Suryawan \& Widhiada, 2015). Salah satu metode penyortiran sampah dapat dilakukan dengan prinsip pengayakan merupakan proses pemisahan berbagai campuran pertikel padatan yang mempunyai berbagai jenis ukuran bahan dengan menggunakan ayakan, proses pengyakan dapat kita ketahui sebagai pemisah yang ukuranya tidak seragam (Laili, 2010). Dengan demikian dapat kita definisikan sebagai salah satu metode pemisahan berbagai campuran partikel padat sehingga didapatkan ukuran partikel yang seragam serta terbebas dari ukuran yang berbeda dengan menggunkan pengayakan.

Penelitian ini bertujuan untuk menghasilkan rancangan mesin pamilah sampah organik dan non organik yang efisien dan sesusai kebutuhan, rancangan mesin pemilah sampah yang berguna agar sampah dapat dipisahkan dengan hasil dari sortasi mesin pemilah ini merupah sampah organik dan non organik dengan berbagai ukuran, serta dengan mengutamakan efisiensi waktu yang dibutuhkan ketika memilah sampah 
sehingga sampah dapat di daur ulang menjadi barang yang bermanfaat dan memiliki nilai ekonomis (French, Gravdahl, \& French, 1985). Pada umunya prinsip pengayakan merupakan proses pemisahan berbagai campuran pertikel padatan yang mempunyai berbagai jenis ukuran bahan dengan menggunakan ayakan, proses pengyakan dapat kita ketahui sebagai pemisah yang ukuranya tidak seragam.

\section{Metode Penelitian}

Dalam peelitian ini akan membuat rancangan mesin peilah sampah kapasitas 50 $\mathrm{kg} / \mathrm{jam}$, yang dimana akan dipilih desain yang memenuhi unsur material requirement, processing requirements, modular desain dan spesifikasi teknik. Dalam rancangan metodelogi penelitian merupakan suatu alur proses langkah-langkah yang akan dilakukan dengan tujuan dapat memberikan hasil dari tujuan penelitian berdasarkan batasan dan rumusan masalah (Fitrah, 2018). Metodologi penelitian merupakan metode perancangan penelitian yang memberikan arahan bagi pelaksanaan sehingga data yang dibutuhkan dapat dikumpulkan, penulisan tugas akhir ini memberikan langkah-langkah yang akan dilakukan yang akan mendapatkan hasil dari tujuan penelitian (Rukajat, 2018).

Perancangan merupakan sebuah langkah awal dalam mewujudkan suatu produk yang dibutuhkan untuk mempermudah suatu pekerjaan atau kegiatan manusia. Pada awalnya untuk menguasai cara merancang dilakukan dengan proses magang dengan mempelajari, mengamati dan mengikuti langkah-langkah yang dilakukan oleh seorang perancang yang telah memiliki pengalaman dalam proses merancang suatu produk (Zariatin, 2016) (Priadythama, Susmartini, \& Nugroho, 2017). Saat ini terdapat berbagai macam metode perancangan yang bisa digunakan untuk merancang sebuah produk contohnya seperti metode French, Pahl and Beitz, Ulman, VDI (Verein Deutcher Ingenieure), dan metode Ibrahim Zeid. Dalam perkembangannya proses perancangan suatu produk telah dirumuskan kedalam beberapa tahap atau beberapa fase yang dapat memudahkan dalam tahap mengembangkan ide rancangan, jenis rancangan, spesifikasi rancangan, dan kategori rancangan. Manfaat menggunakan metode perancangan adalah dapat menyelesaikan berbagai macam kebutuhan akan suatu produk untuk dapat memenuhi kriteria dan keinginan dari konsumen (Wiraghani \& Prasnowo, 2017).

Pada satu proses perancangan tentunya diperlukan suatu alur atau urutan pembuatan pengerjaan yang akan dilakukan kedepannya, bertujuan agar system perancangan yang dibuat menjadi lebih terarah dan mudah dalam memecahkan masalah yang ada. Menggunakan metode french, metode ini merupakan salah satu metode perancangan yang umumnya digunakan yang dimulai dari tahapan perencanaan yang berdasarkan kebutuhan masyarakat blok diagram proses desain pada perancangan alat pemilah sampah ini mengacu pada metode perancangan French (French et al., 1985). Seperti pada gambar 1. Diagram alir penelitian.

Pemilihan metode French dikarenakan metode ini mampu mengakomodir kebutuhan data dengan lebih mudah (Zariatin, 2016). 

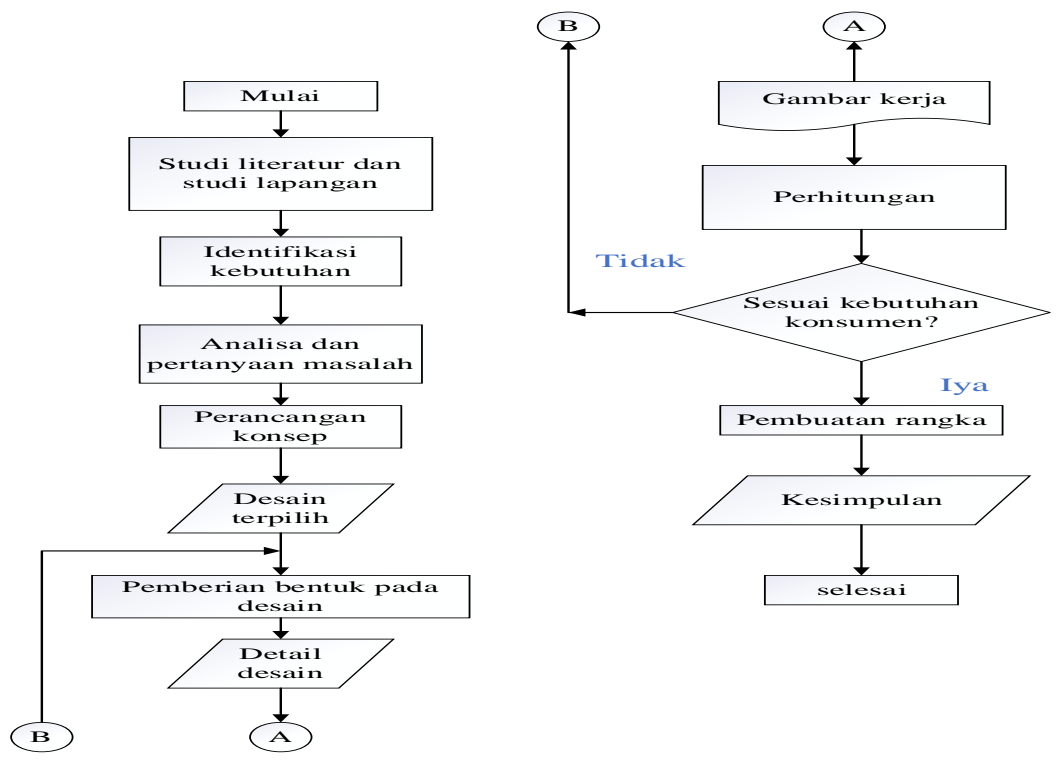

\section{Gambar 1 \\ Diagram alir penelitian}

Agar mengetahui lebih jelas dari metodologi penelitan ini merupakan penjelasan dari diagram alir proses perancangan:

a. Studi literatur dan lapangan tahap ini untuk mencari literatur pada jurnal, buku, referensi atau penelitian yang sudah dipublikasikan. Tujuan dari studi literatur ini untuk mendapatkan teori dasar, permasalahan informasi yang nanti akan dibutuhkan pada penelitian.

b. Identifakasi kebutuhan merupakan pengumpulan data atau informasi yang diperlukan dari mesin pemilah sampah untuk mengetahui kebutuhan apa yang akan dilakukan nanti. Identifikasi dan analisa kebutuhan dilakukan dengan mengobservasi, identifikasi permasalahan, analisa kebutuhan data. Perancangan mesin pemilah sampah kapasitas $50 \mathrm{~kg} / \mathrm{jam}$, tahapan untuk melakukan kebutuhan dan keinginan dari alat ini yang dimana dibuatlah Form kuisioner yang bertujuan agar alat yang akan dikembangkan nantinya dapat sesuai dengan kebutuhan masyarakat atau konsumen

c. Analisis masalah dan pernyataan masalah fase analisa masalah ini bertujuan untuk mengidentifikasi kebutuhan suatu permasalah yang didapat untuk dapat dipenuhi secara tepat dan sesuai yang mungkin atau diinginkan yang akan dibahas pada penelitian mesin pemilah sampah.

d. Perancangan konsep ini bertujuan untuk menghasilkan pilihanpilhan alternatif dari konsep yang dibuat, yang dimana perancangan skema dari perancangan konsep yang sudah dibuat ini berbentuk sketsa dari beberapa plihan konsep.

e. Desain terpilih memilih atau menyeleksi desain dari beberapa varian konsep yang telah dibuat sedemikian rupa. Proses penyeleksian ini dilakukan karna untuk dapat menentukan mana desain terbaik yang sesuai kebutuhan.

f. Pemberian bentuk pada desain proses ini merupakan pembuatan model dari desain varian yang telah terpilah proses pembentukan desain ini digambar hingga mencapai 
gambar 3D melalui software sehingga gambar kerja ini dapat dilakukan ke fase berikutnya yaitu menganalisis kekuatan rangka dengan cara simulasi software

g. Detail desain ini tahapan pemberian bentuk 3D maka, setelah itu akan diberkan detail desain secara lengkap seperi bill of material, ukuran benda teloransi ukuran dan sebagainya.

h. Perhitungan dan analisa ini dilakukan perhitungan kebutuhan motor listrik serta menghitung pada motor listrik menentukan torsi (Masudi, 2015). Diketahui pembebanan pada rangka ayakan serta mesh ayakan $4 \mathrm{~kg}$, kemudian berat pulley 0,7 $\mathrm{kg}$ dan jari-jari pembebana $220 \mathrm{~mm}$ akan dilakukan perhitungan sebagai berikut. Pemilihan motor yang Diperlukan Untuk mencari spesifikasi motor yang diperlukan untuk mesin pemilah sampah diketahuai nilai force $2,9 \mathrm{~N}$, lalu torsi yang didapat 6,259 N.m dan kecepatan motor 100 rpm (dengan asumsi).

Untuk menghitung kebutuhan spesifikasi:

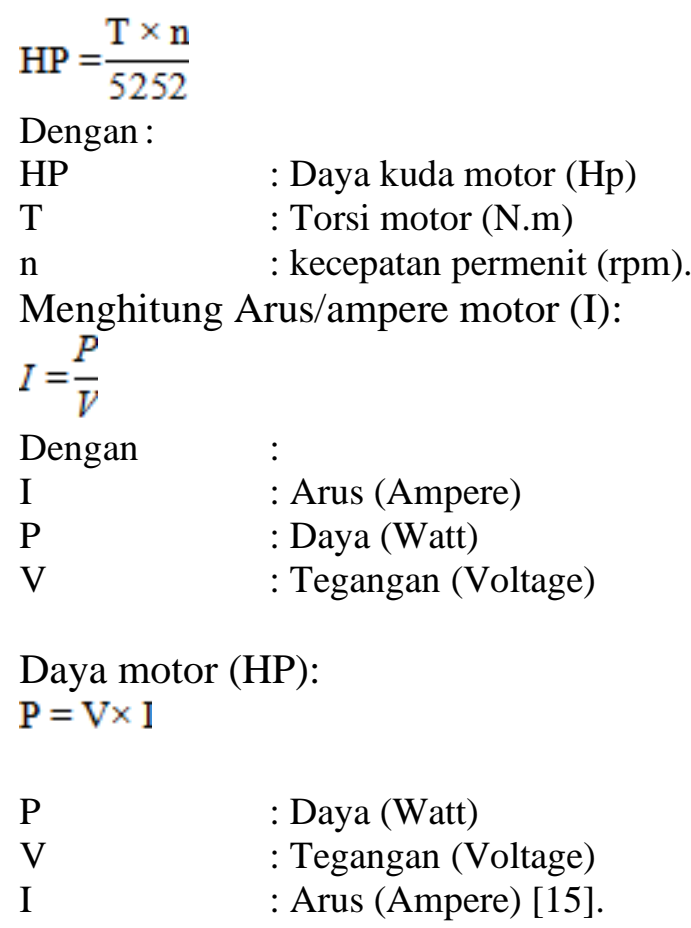

i. Pembuatan rangka Setelah perhitungan analisis kekuatan dan penentuan material yang digunakan, selanjutnya pembuatan rangka berdasarkan pada metode DFMA (Design For Manufacturing Assembly), metode ini menjelaskan tahapan proses manufaktur kontruksi rangka (Priadythama et al., 2017).

j. Kesimpulan fase ini merupakan pembahasan kesimpulan dan saran penelitian yang telah dilakukan.

\section{Hasil dan Pembahasan}

\section{A. Identifikasi kebutuhan}

Identifikasi dan analisa kebutuhan dilakukan dengan mengobservasi, identifikasi permasalahan, analisa kebutuhan data. Perancangan mesin pemilah 
sampah kapasitas $50 \mathrm{~kg} / \mathrm{jam}$, tahapan untuk melakukan kebutuhan dan keinginan dari alat ini yang dimana dibuatlah Form kuisioner yang bertujuan agar alat yang akan dikembangkan nantinya dapat sesuai dengan kebutuhan masyarakat atau konsumen (Liansari, Novirani, \& Subagja, 2016).

Penjelasan mendefinisikan tugas dengan cara mengklasifikasi tugas tersebut kedalam daftar persyaratan, daftar persyaratan ini terdiri dari demand and wishes, demand merupakan persyaratan produk, yang merupakan persyaratan yang jika tidak terpenuhi maka produk akan gagal, wishes merupakan persyaratan yang diinginkan apabila dimungkinkan persyaratan tersebut dilakukan, demand and wishes diproleh dari perbandingan alat yang terdapat dipasaran saat ini.

Tabel 2

Demand and wishes

\begin{tabular}{ccc}
\hline No & Tingkat Kebutuhan D/W & Uraian \\
\hline 1 & D & Aman saat dioperasikan \\
\hline 2 & W & Rangka mesin pemilah sampah \\
\hline 3 & D & $\begin{array}{c}\text { Mesih pemilah bakar tidak bolos } \\
\text { dipergunakan mudah }\end{array}$ \\
\hline 4 & W & $\begin{array}{c}\text { Desain ergonomis untuk mempermudah } \\
\text { pengopasian }\end{array}$ \\
\hline 5 & D & Mesin pemilah sampah tidak bising \\
\hline 6 & W & Perawatan mesin mudah \\
\hline 7 & D & Sperpart mudah didapat di pasaran \\
\hline 8 & W
\end{tabular}

Keterangan

D : demand

W : wishes

\section{B. Diagram Fungsi}

Hasil dari demand and wishes, tahapan perancangan berikutnya membuat struktur fungsi kedalam diagram-diagram yang menunjukan sebuah hubungan antara input and output yang berupa aliran energi, materi dan sinyal pembuatan perancangan yang pertama membuat blok fungsi untuk menjelaskan input pertama dari energi. Material dan sinyal mendapatkan keluaran yang berbeda

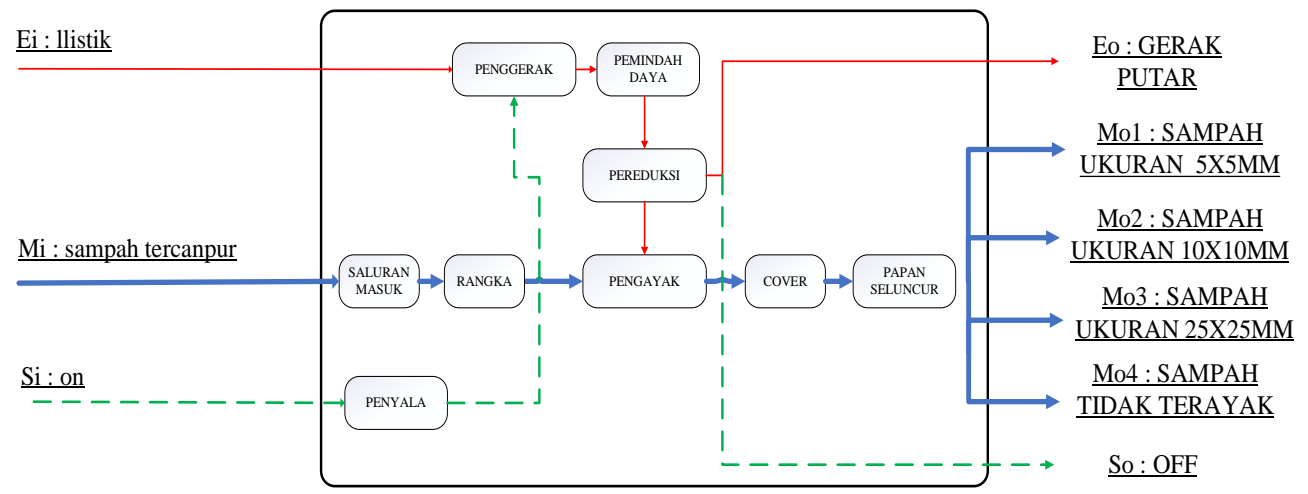

Gambar 2

Blok Fungsi Alat Pemilah Sampah 
Pada mesin pemilah sampah dimana dari (input) mesin ini yaitu sampah organik dan non-organik yang terdapat di internal universitas Pancasila hasil dari sotasi (output) mesin pemilah ini merupah sampah organik dan non organik dengan berbagai ukuran. dengan ukaran sampah 5x5, ukaran sampah 10x10, ukaran sampah $25 \times 25$ serta sampah tidak terayak. Untuk tahap pertama nyalakan mesin pemilahan sampah kemudian masukan sampah tercampur baik organik dan non organik kedalam mesin pemilah sampah. Tahap kedua rangka ayakan mesin pemilah akan digerakan oleh motor listrik dengan gerakan berputar (berotasi). Tahap ketiga sampah tercampur tersebut akan jatuh ke papan seluncur sesuai dengan ukuran masing-masing lubang ayakan.

\section{Perancangan Konsep}

Pada perancangan konsep ini bertujuan untuk menghasilkan pilihan-pilhan alternatif dari konsep yang dibuat, yang dimana perancangan skema dari perancangan konsep yang sudah dibuat ini berbentuk sketsa dari beberapa plihan konsep yang kemudian akan dilakukan evaluasi agar didapat suatu konsep yang baik dan dapat diterima konsumen. Perancangan konsep memerlukan Pinsip solusi yang menjelaskan tentang melengkapi sub fungsi dengan cara memilih dengan varian yang telah dibuat oleh perancang dengan cara pemilihan dan mengkombinasikan berbagai varian sehingga didapatkan berbagai macam varian dimana satu diantara akan dijadiakan sebagai varian yang terbaik. konsep ini bertujuan untuk menghasilkan pilihan-pilhan alternatif dari konsep yang dibuat, yang dimana perancangan skema dari perancangan konsep yang sudah dibuat ini berbentuk sketsa dari beberapa plihan konsep yang kemudian akan dilakukan evaluasi agar didapat suatu konsep yang baik dan dapat diterima konsumen. Tahapan berikunya yang harus dilakukan (Nafsan Upara1, 2019). 


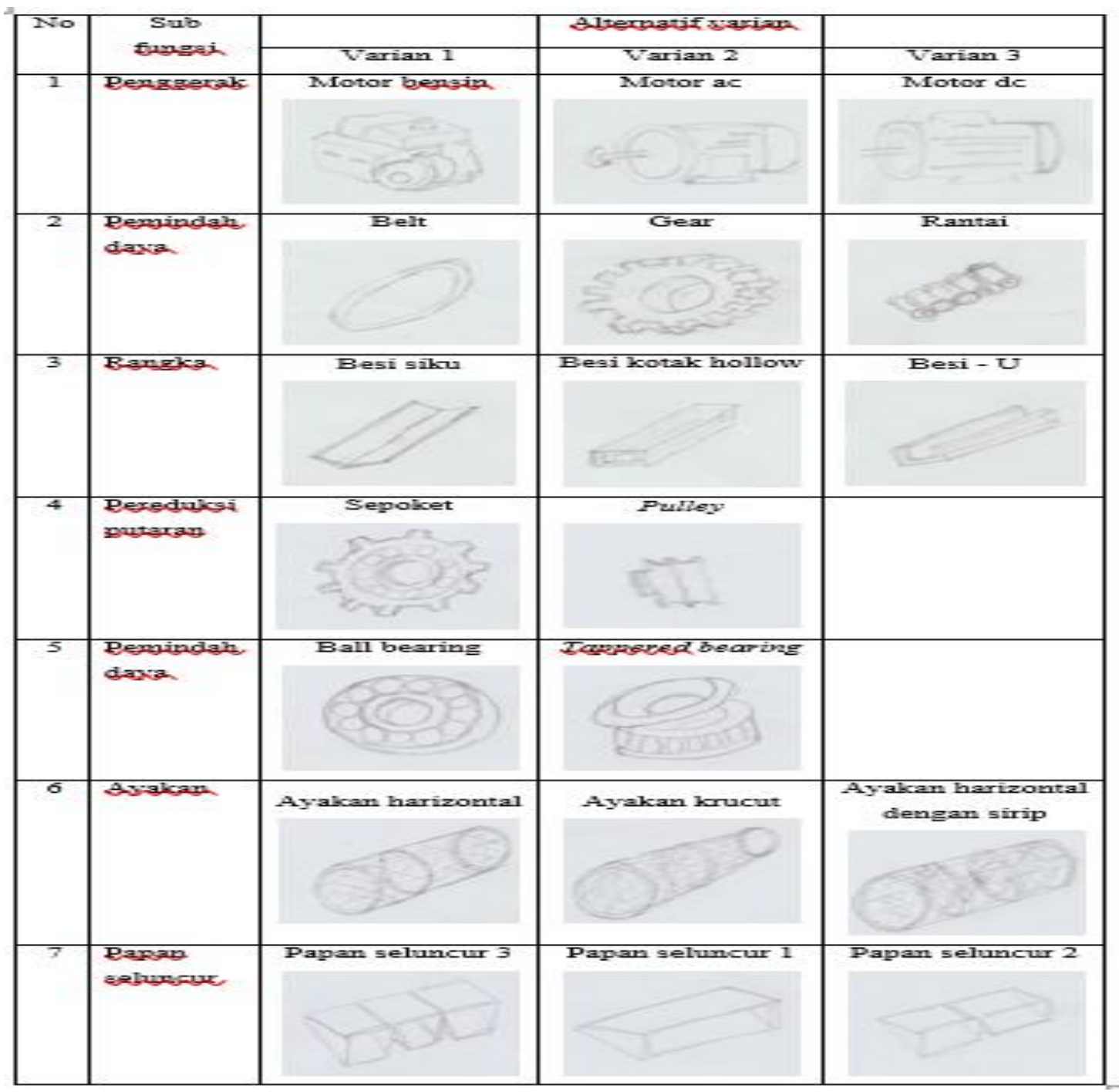

Gambar 3

Kombinasi solusi perancangan mesin pemilah sampah

Dari table diatas didapatkan dua varian dari hasil kombinasi dari berbagai komonen varian berikut hasil kombinasi dari prinsip solusi alat pemilah sampah

a Varian satu (1-1, 2-1, 3-1, 4-, 5-1, 6-1, 7-3), ara kerja mesin pemilah sampah dengan penggerak motor listrik, dengan menggunakan plat L dan pully dan belt sebagai tranmisi, dengan mengunakan ayakan harizontal serta dua keluaran.

b Varian dua (1-2, 2-1, 3-3, 4-2, 5-1, 6-2, 7-1), cara kerja; mesin pemilah sampah dengan penggerak motor listrik, dengan menggunakan plat $U$ dan pully dan belt sebagai tranmisi, dengan mengunakan ayakan krucut serta tiga keluaran.

Dengan adanya kombinasi prinsip solusi perancangan mesin pamilah sampah pada Tabel 2. di atas, maka selanjutnya akan dipilih kombinasi yang terbaik untuk didesain dan dibuat mesin pamilah sampah.

\section{Karakteristik pemilihan Desain}

Karakteristik produk berkualitias merupakan tujuan dari mengevaluasi satiap varian yang telah dibentuk dengan menentukan parameter yang dinilai dengan 
bembobotan. Yang merupakan landasan pembobotan atau penilaian dari penelitian kombinasi dibatasi dari karakteristik produk berkualitas dan sesuai degan kebutuhan konsumen, kebutuhan dapat menjelaskan tentang berbagai kebutuhan yang diperoleh dari permasalahan produk yang akan dibuat, serta pengumpulan data informasi (Nafsan Upara1, 2019). Pengumpulan data dilakukan dengan observasi, bila kebutuhan yang diinginkan sudah di ketahui dan dimengerti dengan baik, barulah suatu produk dapat dirancang dengan menggunakan tahapan yang sesuai agar menghasilkan suatu produk yang memenuhi kebutuhan tersebut.

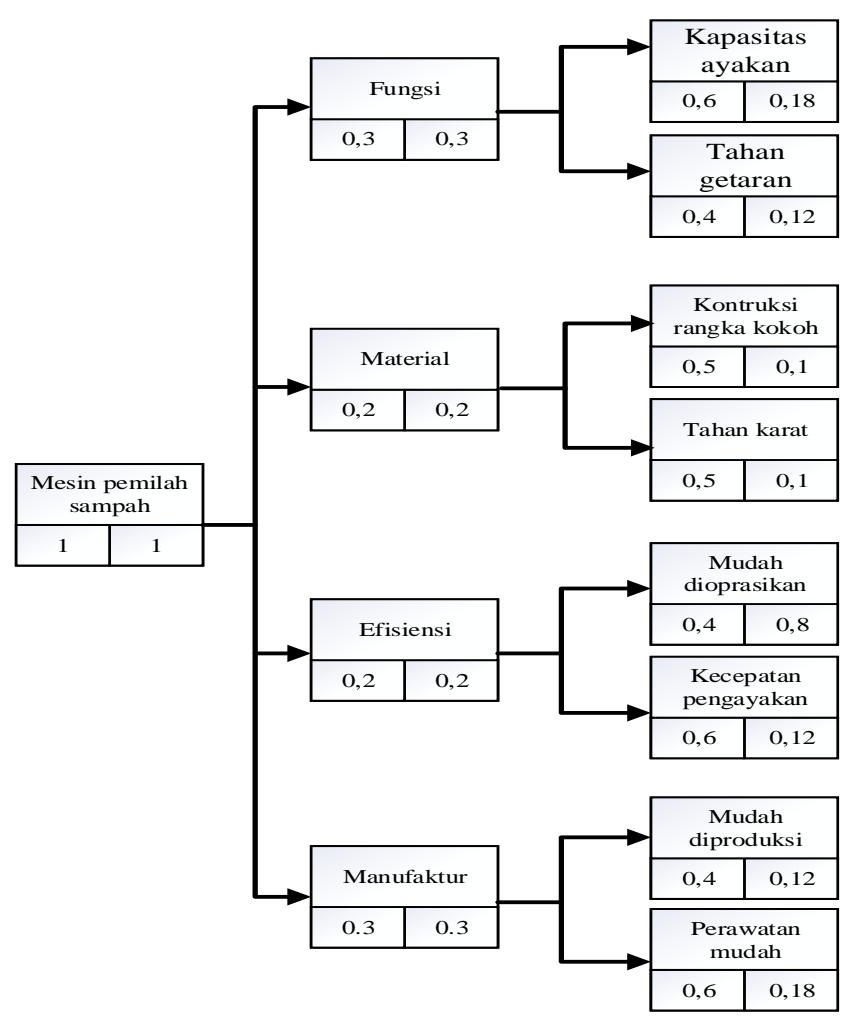

Gambar 4

Pohon keputusan

Berikut merupakan tabel pembobotan yang dimana terdapat varian 1 dan varian 2 dari hasil pembobotan didapatkan desain terpilih sebagai berikut

Table 3

Pembobotan varian-varian

\begin{tabular}{ccccccc}
\hline No & Kriteria & Bobot & \multicolumn{2}{c}{ Varian a } & \multicolumn{2}{c}{ Varian b } \\
\cline { 3 - 7 } & & Nilai & $\begin{array}{c}\text { Bobot } \\
\text { nilai }\end{array}$ & Nilai & $\begin{array}{c}\text { Bobot } \\
\text { nilai }\end{array}$ \\
\hline 1 & $\begin{array}{c}\text { Kapasistas } \\
\text { ayakan }\end{array}$ & 0,18 & 4 & 0,75 & 4 & 0,75 \\
\hline 2 & $\begin{array}{c}\text { Tahan } \\
\text { Getaran }\end{array}$ & 0,12 & 4 & 0,48 & 3 & 0,36 \\
\hline 3 & $\begin{array}{c}\text { Kontruksi } \\
\text { rangka kokoh }\end{array}$ & 0,1 & 4 & 0,4 & 4 & 0,4 \\
\hline
\end{tabular}




\begin{tabular}{ccccccc}
\hline 4 & Tahan karat & 0,1 & 3 & 0,3 & 3 & 0,3 \\
\hline 5 & $\begin{array}{c}\text { Mudah } \\
\text { dioperasikan }\end{array}$ & 0,8 & 4 & 0,32 & 4 & 0,32 \\
\hline 6 & $\begin{array}{c}\text { Kecepatan } \\
\text { pengayakan }\end{array}$ & 0,12 & 4 & 0,36 & 4 & 0,48 \\
\hline 7 & $\begin{array}{c}\text { Mudah } \\
\text { dioperasikan }\end{array}$ & 0,12 & 4 & 0,48 & 5 & 0,6 \\
\hline 8 & $\begin{array}{c}\text { Perawatan } \\
\text { mudah }\end{array}$ & 0,18 & 4 & 0,72 & 5 & 0,9 \\
\hline & Total & 4 & 3,90 & & 4,08 \\
\hline
\end{tabular}

Berikut untuk mendapatkan desain yang akan terpilih dari kedua varian maka varian-varian yang terpilih akan dilakukanya tahapan pembobotan tertinggi maka varian tersebut akan terpilih, seperti paada tabel 4. Pembobotan varian ini bertujuan untuk memilah desain terbaik berdasarkan karakteristik produk berkualitas.

\section{E. Desain Terpilih}

Berikut ini adalah fase terakhir dari pemilihan desain yaitu desain terpilih, sehingga dapat fase ini merencanakan proses pembentukan rancangan desain awal yang sesuai konsep dari sketsa terpilih. Yang mana proses ini desain yang terpilih dan sudah diberi bentuk 3D maka, setelah itu akan diberikan detail desain secara lengkap seperi bill of material, ukuran benda (dimensi ukuran secara lengkap), teloransi, tanda baca dan sebagainya (De Benedetto \& Klemeš, 2010). Gambar 4 menerankan tentang detail desain terpilih

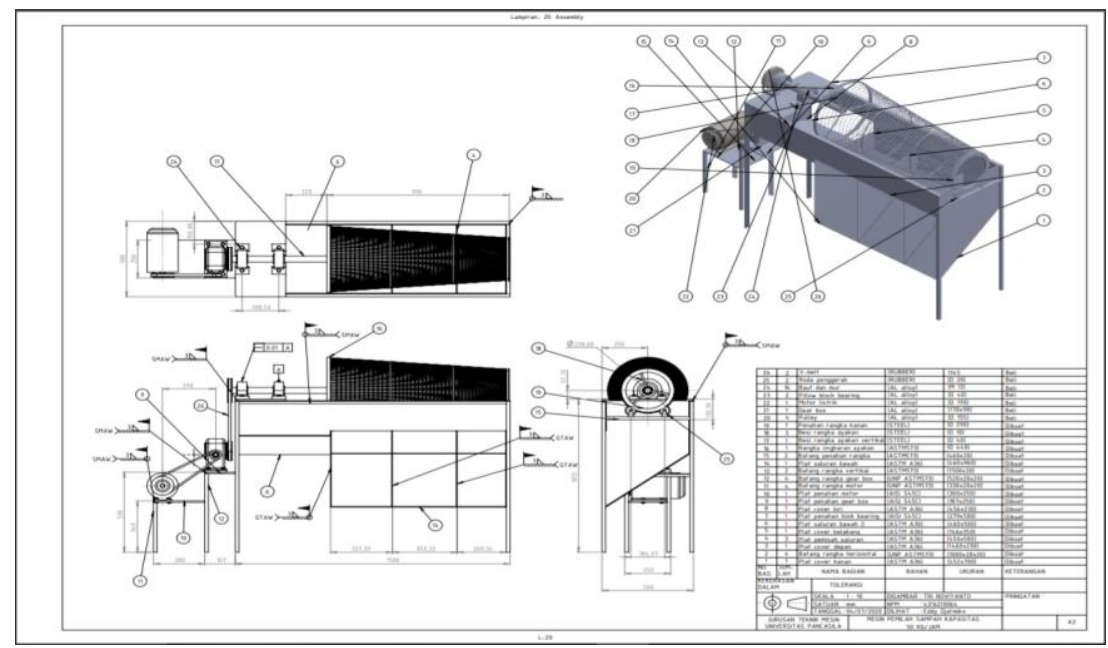

Gambar 5

Desain Terpilih 
Tabel 5

Bagian dan fungsi rangka mesin pemilah sampah kapasitas $50 \mathrm{~kg} / \mathrm{jam}$

\begin{tabular}{|c|c|c|c|c|}
\hline No. & $\begin{array}{c}\text { Nama } \\
\text { Komponen }\end{array}$ & Fungsi & Jumlah & Keterangan \\
\hline 1 & Plat cover kanan & $\begin{array}{c}\text { Saluran Masuk } \\
\text { Sampah Terayak }\end{array}$ & 1 & Buat \\
\hline 2 & $\begin{array}{c}\text { Batang rangka } \\
\text { horizontal }\end{array}$ & $\begin{array}{c}\text { Penyangga } \\
\text { Rangka Utama }\end{array}$ & 4 & Buat \\
\hline 3 & Plat cover depan & $\begin{array}{c}\text { Saluran Masuk } \\
\text { Sampah Terayak }\end{array}$ & 1 & Buat \\
\hline 4 & $\begin{array}{l}\text { Plat pemisah } \\
\text { saluran }\end{array}$ & $\begin{array}{c}\text { Saluran Masuk } \\
\text { Sampah Terayak }\end{array}$ & 3 & Buat \\
\hline 5 & Plat cover kanan & $\begin{array}{c}\text { Saluran Masuk } \\
\text { Sampah Terayak }\end{array}$ & 1 & Buat \\
\hline 6 & $\begin{array}{l}\text { Plat saluran } \\
\text { bawah } 2\end{array}$ & $\begin{array}{c}\text { Saluran Masuk } \\
\text { Sampah Tidak } \\
\text { Terayak }\end{array}$ & 1 & Buat \\
\hline 7 & $\begin{array}{c}\text { Plat penahan } \\
\text { blok boarding }\end{array}$ & $\begin{array}{c}\text { Landasan Pillow } \\
\text { Blok Boarding }\end{array}$ & 1 & Buat \\
\hline 8 & Plat cover kiri & $\begin{array}{c}\text { Saluran Masuk } \\
\text { Sampah Tidak } \\
\text { Terayak }\end{array}$ & 4 & Buat \\
\hline 9 & $\begin{array}{c}\text { Plat penahan } \\
\text { gear box }\end{array}$ & $\begin{array}{c}\text { Penyangga Gear } \\
\text { Box }\end{array}$ & 1 & Buat \\
\hline 10 & $\begin{array}{l}\text { Plat penahan } \\
\text { motor }\end{array}$ & $\begin{array}{c}\text { Penyangga } \\
\text { Motor }\end{array}$ & 3 & Buat \\
\hline 11 & $\begin{array}{c}\text { Batang rangka } \\
\text { motor }\end{array}$ & $\begin{array}{c}\text { Penhat Plat } \\
\text { Penahan Motor }\end{array}$ & 4 & Buat \\
\hline 12 & $\begin{array}{l}\text { Batang rangka } \\
\text { gear box }\end{array}$ & $\begin{array}{c}\text { Penahan Plat } \\
\text { Penahan Gear } \\
\text { Box }\end{array}$ & 4 & Buat \\
\hline 13 & $\begin{array}{c}\text { Batang rangka } \\
\text { vertikal }\end{array}$ & $\begin{array}{c}\text { Penyangga } \\
\text { Rangka Utama }\end{array}$ & 2 & Buat \\
\hline 14 & $\begin{array}{c}\text { Plat salauran } \\
\text { bawah }\end{array}$ & $\begin{array}{c}\text { Saluran Keluar } \\
\text { Sampah Terayak }\end{array}$ & 1 & Buat \\
\hline 15 & $\begin{array}{c}\text { Batang penahan } \\
\text { rangka }\end{array}$ & $\begin{array}{c}\text { Penyangga } \\
\text { Rangka Utama }\end{array}$ & 1 & Buat \\
\hline 16 & $\begin{array}{c}\text { Rangka lingkar } \\
\text { ayakan }\end{array}$ & $\begin{array}{c}\text { Penyangga } \\
\text { Rangka Ayakan }\end{array}$ & 1 & Buat \\
\hline 17 & $\begin{array}{c}\text { Besi rangka } \\
\text { ayakan vertikal }\end{array}$ & $\begin{array}{l}\text { Penghubung } \\
\text { Ayakan Dengan } \\
\text { Penggerak }\end{array}$ & 1 & Buat \\
\hline 18 & $\begin{array}{c}\text { Besi rangka } \\
\text { ayakan }\end{array}$ & $\begin{array}{c}\text { Penyangga } \\
\text { Rangka Ayakan }\end{array}$ & 3 & Buat \\
\hline 19 & $\begin{array}{c}\text { Penahan rangka } \\
\text { kakanan }\end{array}$ & $\begin{array}{c}\text { Menahan } \\
\text { Rangka Ayakan }\end{array}$ & 1 & Buat \\
\hline 20 & Pulley & $\begin{array}{c}\text { Menahan } \\
\text { Rangka Ayakan }\end{array}$ & 4 & Beli \\
\hline 21 & Gear box & Penggerak & 1 & Buat \\
\hline 22 & Motor listrik & Penggerak & 1 & Buat \\
\hline 23 & Pillow blok & Penahan Rangka & 2 & Buat \\
\hline
\end{tabular}




\begin{tabular}{ccccc}
\hline boarding & Ayakan & & \\
\hline 24 & Baut dan mur & $\begin{array}{c}\text { Penyambung } \\
\text { Komponen } \\
\text { Rangka }\end{array}$ & 16 & Buat \\
\hline 25 & Roda penggerak & $\begin{array}{c}\text { Penahan Rangka } \\
\text { Ayakan }\end{array}$ & 2 & Buat \\
\hline 26 & V-Belt & Pereduksi & 2 & \\
\hline
\end{tabular}

Dengan adanya Tabel 4. Dapat diketahui jumlah komponen dan fungsi setiap komponen serta material yang digunakan hal ini sangat penting dikarnakan dapat mempermudah proses prakitan (manufacturing), perakitan dengan komponenkomponen yang lainnya sehingga dapat menjadi suatu produk tanpa harus mengurangi suatu fungsi dari suatu alat yang telah dibuat tersebut dalam menentukan material komponen bahan dan komponen harus yang berstandarisasi dengan pengujian sebelumnya. Serta Pemilihan dan penggunaan material untuk suatu produk nantinya dapat mudah ditemukan dipasaran dengan harga yang terjangkau.

\section{F. Perhitungan perancangan}

Menentukan torsi diketahui pembebanan pada rangka ayakan serta mesh ayakan $4 \mathrm{~kg}$, kemudian berat pulley $0,7 \mathrm{~kg}$ dan jari-jari pembebana $220 \mathrm{~mm}$ akan dilakukan perhitungan sebagai berikut

$m$ : rangka ayakan serta mesh ayakan $2 \mathrm{~kg}+$ pulley $0,9 \mathrm{~kg}$

$$
m: 2,9 \mathrm{~kg}
$$

$F=m \times g$

$F=2.9 \mathrm{~kg} \times 9,81 \frac{\mathrm{m}}{\mathrm{s}^{2}}=28,45 \mathrm{~N}$

$T=F \times r$

$T=28,45 \mathrm{~N} \times 0,22 \mathrm{~m}=6,259 \mathrm{~N} . \mathrm{m}$

Untuk mencari spesifikasi motor yang diperlukan untuk mesin pemilah sampah diketahuai nilai force 2,9 N, lalu torsi yang didapat 6,259 N.m dan kecepatan motor 100 rpm (dengan asumsi).

a. Menghitung kebutuhan spesifikasi

$$
\begin{aligned}
& \mathrm{HP}=\frac{\mathrm{T} \times \mathrm{n}}{5252} \\
& \mathrm{HP}=\frac{6,259 \mathrm{~N} \cdot \mathrm{m} \times 100 \mathrm{rpm}}{5252} \\
& =(0.119 \mathrm{HP})(88,73 \mathrm{watt})
\end{aligned}
$$

Menghitung arus yang diperlukan degan perkiraan tegangan $220 \mathrm{~V}, 88,973$ watt $=$ $0,08873 \mathrm{~kW}$. 
b. Arus/ampere motor (I) :

$$
\begin{aligned}
I & =\frac{P}{V} \\
I & =\frac{88,73 \text { watt }}{220 \mathrm{~V}}=0,403 \text { Amper }
\end{aligned}
$$

c. Daya motor (HP)

$$
\begin{gathered}
\mathrm{P}=\mathrm{V} \times \mathbf{I} \\
\mathrm{P}=220 \mathrm{~V} \times 0,403 \mathrm{~A}=88,66 \text { watt }=0,08866 \mathrm{~kW}=(0,119 \mathrm{HP})
\end{gathered}
$$

Didapat perhitungan diatas kita dapat daya motor yang dibutuhkan untuk memutar rangka ayakan dan mash sebesar 2,9 kg. setara dengan $0.119 \mathrm{HP}$ oleh sebab itu disini peneliti meyesuaikan dengan spesifikasi yang berada di pasaran mendekati perhitungan maka dipilih motor $0.5 \mathrm{HP}$, setelah didapat spesifikasi motor yang akan digunakan menggunakan motor AC 2 phasa dengan putaran motor sesuai spesifikasi yang terdapat dipasaran $1425 \mathrm{rpm}$ dan frekuensi $50 \mathrm{~Hz}$.

\section{Kesimpulan}

Dari hasil konsep perancangan mesin pemilah sampah didapatkan dua konsep varian yaitu varian 1 dan varian 2 , yang dimana dari kedua varian konsep tersebut akan dipilih berdasarkan dari hasil pembobotan varian yang dimana varian 1 mendapatkan bobot nilai $(3,90)$ sedangkan dari varian 2 mendapatkan bobot nilai $(4,08)$ dari kedua konsep varian mesin pemilah sampah maka dipilih bobot nilai yang terbesar yaitu varian 2 (4,08). Dari hasil perhitungan motor pada mesin peilah sampah mendapatkan hasil perhitungan daya motor listrik yang dibutuhkan untuk memutar ayakan, dengan 0.193 Hp oleh sebab itu disini peneliti meyesuaikan dengan spesifikasi yang berada dipasaran mendekati perhitungan maka dipilih motor $0,5 \mathrm{HP}$. 


\section{BIBLIOGRAFI}

De Benedetto, Luca, \& Klemeš, Jiř́i. (2010). The environmental bill of material and technology routing: an integrated LCA approach. Clean Technologies and Environmental Policy, 12(2), 191-196. Google Scholar

Fitrah, Muh. (2018). Metodologi penelitian: penelitian kualitatif, tindakan kelas \& studi kasus. CV Jejak (Jejak Publisher). Google Scholar

French, Michael J., Gravdahl, J. T., \& French, M. J. (1985). Conceptual design for engineers. Springer. Google Scholar

Laili, Rizki Ridha. (2010). Laporan magang di PT. Mayafood Industries Pekalongan Jawa Tengah (proses pembuatan tepung ikan). Google Scholar

Liansari, Gita Permata, Novirani, Dwi, \& Subagja, Rifqi Nanda. (2016). Rancangan blueprint alat cetak kue balok yang ergonomis dengan metode ergonomic function deployment (EFD). Jurnal Rekayasa Sistem Industri, 5(2), 106-117. Google Scholar

Masudi, Nanang. (2015). Desain Controller Motor Bldc Untuk Meningkatkan Performa Output (Daya) Pada Sepeda Motor Listrik. Institut Teknologi Sepuluh Nopember. Google Scholar

Mulyadin, R. Mohamad, Iqbal, Mohamad, \& Ariawan, Kuncoro. (2018). Konflik pengelolaan sampah di DKI Jakarta dan upaya mengatasinya. Jurnal Analisis Kebijakan Kehutanan, 15(2), 179-191. Google Scholar

Nafsan Upara1, Mochamad Zaelani. (2019). Rancang Bangun Mesin Shaker Untuk Jerrycan Kemasan 2x5 Kilogram Skala Laboratorium. Seminar Dan Konferensi Nasional IDEC. Google Scholar

Priadythama, Ilham, Susmartini, Susy, \& Nugroho, Alviandi Wahyu. (2017). Penerapan DFMA untuk Low Cost High Customization Product. Performa: Media Ilmiah Teknik Industri, 16(1). Google Scholar

Purwaningrum, Pramiati. (2016). Upaya mengurangi timbulan sampah plastik di lingkungan. Indonesian Journal of Urban and Environmental Technology, 8(2), 141-147. Google Scholar

Putu Agus Suryawan, I. Gede, \& Widhiada, I. Wayan. (2015). Mesin Pemisah dan Pencacah Sampah Organik dan Plastik Untuk Bahan Kompos. Google Scholar

Rukajat, Ajat. (2018). Pendekatan Penelitian Kualitatif (Qualitative Research Approach). Deepublish. Google Scholar

Sampah Perkotaan, Analisis SWOT. (2016). Strategi Pengelolaan Sampah Rumah Tangga Di Kota Tarakan Kalimantan Utara. Jurnal Ekonomi Pembangunan, 5(0), 
Tri Noviyanto, Eka Maulana, Eddy Djadmiko

N0-3. Google Scholar

Wiraghani, Sulung Rahmawan, \& Prasnowo, M. Adhi. (2017). Perancangan dan Pengembangan Produk Alat Potong Sol Sandal. Teknika: Engineering and Sains Journal, 1(1), 73-76. Google Scholar

Zariatin, Dede Lia. (2016). Rancang Bangun Simulator Sistem Pengepakan Produk Berbasis Programmable Logic Control. SINTEK JURNAL: Jurnal Ilmiah Teknik Mesin, 10(2). Google Scholar

\section{Copyright holder:}

Tri Noviyanto, Eka Maulana, Eddy Djadmiko (2021)

First publication right:

Syntax Literate: Jurnal Ilmiah Indonesia

This article is licensed under:

(cc) (i) (?) 